\title{
Estrogen-Induced Activation of Mitogen-Activated Protein Kinase in Cerebral Cortical Explants: Convergence of Estrogen and Neurotrophin Signaling Pathways
}

\author{
Meharvan Singh, ${ }^{1}$ György Sétáló Jr, ${ }^{1,2}$ Xiaoping Guan, ${ }^{1}$ Matthew Warren, ${ }^{1}$ and C. Dominique Toran-Allerand 1 \\ ${ }^{1}$ Departments of Anatomy and Cell Biology and Neurology and Centers for Neurobiology and Behavior and Reproductive \\ Sciences, Columbia University College of Physicians and Surgeons, New York, New York 10032, and 2Department of \\ Biology, University Medical School of Pécs, Pécs H-7643, Hungary
}

\begin{abstract}
We have shown that estrogen elicits a selective enhancement of the growth and differentiation of axons and dendrites (neurites) in the developing CNS. We subsequently demonstrated widespread colocalization of estrogen and neurotrophin receptors (trk) within developing forebrain neurons and reciprocal transcriptional regulation of these receptors by their ligands. Using organotypic explants of the cerebral cortex, we tested the hypothesis that estrogen/neurotrophin receptor coexpression also may result in convergence or cross-coupling of their signaling pathways. Estradiol elicited rapid (within 5-15 min) tyrosine phosphorylation/activation of the mitogen-activated protein (MAP) kinases, ERK1 and ERK2, that persisted for at least 2 hr. This extracellular signal-regulated protein kinase (ERK) activation was inhibited successfully by the MEK1 inhibitor PD98059, but not by the estrogen receptor (ER) antagonist
\end{abstract}

ICI 182,780, and did not appear to result from estradiol-induced activation of trk. Furthermore, we also found that estradiol elicited an increase in B-Raf kinase activity. The latter and subsequent downstream events leading to ERK activation may be a consequence of our documentation of a multimeric complex consisting of, at least, the ER, hsp90, and B-Raf. These novel findings provide an alternative mechanism for some of the estrogen actions in the developing CNS and could explain not only some of the very rapid effects of estrogen but also the ability of estrogen and neurotrophins to regulate the same broad array of cytoskeletal and growth-associated genes involved in neurite growth and differentiation.

Key words: estradiol; estrogen receptor; ERK; neurotrophins; signal transduction; cross-coupling; brain; cerebral cortex
Estrogen and numerous growth factors, including the neurotrophins (NGF, BDNF, NT-3, NT-4/5), play important roles associated with neuronal differentiation and survival (ToranAllerand, 1996a,b). We previously showed that estrogen elicits significant enhancement of neurite growth and differentiation within organotypic explant cultures of the hypothalamus, preoptic area, and cerebral cortex (Toran-Allerand, 1976, 1980, 1984) and that estrogen and neurotrophin receptors colocalize in developing forebrain neurons (Toran-Allerand et al., 1992; Miranda et al., 1993). This pattern of coexpression suggested the potential

\footnotetext{
Received March 13, 1998; revised Nov. 6, 1998; accepted Nov. 25, 1998.

This work was supported in part by grants from National Institutes of Health (National Institute on Aging, National Institute of Mental Health, and National Science Foundation), the Alzheimer's Association/Burks B. Lapham grant, the Bader Foundation, and an Alcohol, Drug Abuse, and Mental Health Administration Research Scientist Award to C.D.T.-A. We thank Hae-Jung Chung, Cynthia Leung, and Dr. Elisabetta Mauri for their expert technical assistance. We are indebted to Dr. Lloyd A. Greene (Columbia University, NY) for his technical advice, for critically reviewing this manuscript, and for providing valuable discussions; Dr. David R. Kaplan (McGill University, Montréal, Québec, Canada) for valuable discussions and for the gift of the anti-pan trk 203 antibody; Dr. Robert A. Rush (Flinders University, Adelaide, Australia) for the anti-rat blocking antibodies to BDNF and NT-3; Dr. Margaret Shupnik (University of Virginia, Charlottesville, VA) for the anti-estrogen receptor antibody (C1355); and Dr. Alan E. Wakeling (Zeneca Pharmaceuticals, Cheshire, UK) for the gift of ICI 182,780 and ICI 164,384. We also thank Drs. James Angelastro and Matthew Cunningham (Columbia University) for their technical advice.

Parts of this paper have been published previously at the 26th and 27th Annual Meetings of the Society for Neuroscience, Washington, DC, November 16-21, 1996, and New Orleans, LA, October 25-30, 1997, respectively.

Correspondence should be addressed to Dr. Dominique Toran-Allerand, Department of Anatomy and Cell Biology, Columbia University College of Physicians and Surgeons, 650 West 168th Street, BB 1615, New York, NY 10032.

Copyright (C) 1999 Society for Neuroscience $0270-6474 / 99 / 191179-10 \$ 05.00 / 0$
}

for interaction between these two receptor systems. In fact, subsequent studies demonstrated differential and reciprocal regulation of estrogen and nerve growth factor (NGF) receptor mRNAs by their ligands, along with the regulation of estrogen receptor (ER) binding, in adult female rat sensory neurons (Sohrabji et al., 1994b), PC12 cells (Sohrabji et al., 1994a) and cerebral cortical explants (Miranda et al., 1996). In addition, estrogen also has been shown to regulate the levels of NGF and brain-derived neurotrophic factor (BDNF) mRNA expression in the adult rat cerebral cortex (Singh et al., 1995; Sohrabji et al., 1995), olfactory bulb (Sohrabji et al., 1995), and hippocampus (Singh et al., 1995). A critical and, as yet, unanswered question is whether the developmental actions of estrogen on neurite growth and differentiation are mediated directly or result from intermediate steps via modulatory interactions with endogenous growth factors and their signaling pathways.

The classical mechanism of estrogen action requires the binding of intranuclear receptors to specific estrogen response elements (EREs) within DNA, resulting in the regulation of gene expression. This concept, however, inadequately explains the complete and extensive range of actions of estrogen, which include the ability of estrogen to regulate non-ERE-containing genes (Sukovich et al., 1994) and the very rapid (seconds to minutes) effects of estrogen (Chiaia et al., 1983; Garcia-Segura et al., 1987; Migliaccio et al., 1993), collectively suggesting alternative mechanisms of action.

In extraneural targets, interactions between the ER and growth factor signaling pathways (e.g., EGF; TGF- $\alpha /$ TGF- $\beta$; IGF-I, insulin) have been implicated in the mediation of an increasing 
number of estrogen-induced differentiative processes (Read et al., 1989; Kato et al., 1995). For example, the uterotrophic effects of epidermal growth factor (EGF) (Ignar-Trowbridge et al., 1992) and the differentiative effects of insulin on neuroblastoma cells (Patrone et al., 1996) were both found to be estrogen receptordependent. Furthermore, the effect of insulin required the presence of p21Ras, an early signaling component of the mitogenactivated protein (MAP) kinase cascade also used by the neurotrophins. As a result of these observations, taken collectively with the knowledge that estrogen and the neurotrophins can regulate the same cytoskeletal and growth-associated genes [such as MAP-2 (Black et al., 1986; Fischer et al., 1991; Lorenzo et al., 1992), tau microtubule-associated protein (Drubin et al., 1985; Matsuno et al., 1997), $\beta$-tubulin (Guo and Gorski, 1988), and GAP-43 (Costello et al., 1990; Lustig et al., 1991)], we hypothesized that the MAP kinase cascade also may be used by estrogen in its differentiative actions on the CNS.

Here, we report for the first time in the developing brain, which normally expresses wild-type ERs, the rapid activation of the MAP kinase isoforms, extracellular signal-regulated protein kinase-1 (ERK1) and ERK2 by estradiol, an action blocked by the mitogen-activated protein kinase kinase (MEK1) inhibitor PD98059, but not by the ER antagonist ICI 182,780. Moreover, estradiol-induced ERK phosphorylation did not result from trk activation but is likely a consequence of our observed estradiolinduced activation of B-Raf. A possible mechanism for estrogen action is suggested by the work of Jaiswal et al. (1996), which demonstrated an intracellular association between the heat shock protein, hsp90, and B-Raf in PC12 cells. In view of the known association of hsp90 with the ER (Segnitz and Gehring, 1995), we postulated that the ER also may be a component of this putative complex and could be associated with one or more of members of the MAP kinase cascade. We confirmed this in explants of the cerebral cortex, where the ER coimmunoprecipitated with hsp90 and B-Raf, but not with MEK1. These novel findings suggest that the estrogen-induced activation of ERK may occur via direct interaction of the ER in a complex with members of the MAP kinase cascade. Such multimeric complexes would provide intracellular convergence points for the rapid activation of ERK by estrogen and, conversely, support the previously reported regulation of the ER by neurotrophins (Miranda et al., 1996).

\section{MATERIALS AND METHODS}

Tissue culture. Organotypic explants were derived from $\sim 360-\mu \mathrm{m}$-thick hemicoronal slices of postnatal day 2 (P2) frontal and cingulate cerebral cortex (day of birth = P1) or from parasagittal slices of P9 cerebellum, obtained from pups born of timed-pregnant Sprague Dawley rats (ZivicMiller, Allison Park, PA, and Taconic Farms, Germantown, NY) as previously described (Miranda et al., 1996). Explant slices were maintained as roller tube cultures on rat-tail collagen-coated/poly-L-lysineprecoated glass coverslips for $6 \mathrm{~d}$ to allow them to reach the stage of maximal cortical ER expression (Friedman et al., 1983; Gerlach et al., 1983). The steroid-deficient and phenol red-free maintenance nutrient medium (25\% gelding serum, 22.5\% HBSS, 50\% BME, $7.5 \mathrm{mg} / \mathrm{ml}$ glucose, $2 \mathrm{~mm}$ L-glutamine, and $50 \mu \mathrm{g} / \mathrm{ml}$ ascorbic acid) was supplemented with a cocktail of human recombinant neurotrophins $[50 \mathrm{ng} / \mathrm{ml}$ each of NGF, BDNF, NT-3, and NT-4/5 (Genentech, San Francisco, CA, and Intergen, Purchase, NY)] and $17-\beta$ estradiol (10 nM; Sigma, St. Louis, MO). Antibiotics were never used.

Treatment of cultures. After $6 \mathrm{~d}$ in culture a $24 \mathrm{hr}$ washout period was performed, consisting of both omitting exogenously added estradiol and neurotrophins and adding blocking antibodies to rodent NGF (Sigma), BDNF, and NT-3 (gift of R. A. Rush, Flinders University, Adelaide, Australia) (Zhou et al., 1996). For the experiment identifying the effect of the ER antagonist, $1 \mu \mathrm{M}$ ICI 182,780 (gift of A. E. Wakeling, Zeneca Pharmaceuticals, Cheshire, England) or 0.1\% DMSO (vehicle control) was added to the appropriate tubes at this time as well. The next day the explants were pulsed with $10 \mathrm{~nm}$ estradiol for 5, 15, and $30 \mathrm{~min}$ and 1,2, and $4 \mathrm{hr}$ or with $100 \mathrm{ng} / \mathrm{ml}$ of each individual neurotrophin (NGF, BDNF, NT-3, and NT-4/5) administered together as a cocktail for a single $30 \mathrm{~min}$ time point. For the MEK1 inhibition experiment the cultures were pretreated with either the MEK1 inhibitor PD98059 (100 $\mu \mathrm{M}$; New England Biolabs, Beverly, MA) or $0.1 \%$ DMSO for $4-5 \mathrm{hr}$ before the cultures were pulsed with the appropriate estradiol or neurotrophin treatments. We also evaluated the effect of estradiol on cerebellar cultures for which the ER levels (estrogen binding) relative to the cerebral cortex are considerably lower at the postnatal age investigated (C. D. Toran-Allerand and N. J. MacLusky, unpublished observation). Cerebellar cultures were treated either with $10 \mathrm{~nm}$ estradiol for 30 or 60 min or with the neurotrophin cocktail for $30 \mathrm{~min}$.

Tissue processing. Harvested cultures (two to four hemicoronal sections per coverslip) were washed with ice-cold PBS and immersed into lysis buffer containing $50 \mathrm{~mm}$ Tris, pH 7.4, $150 \mathrm{~mm} \mathrm{NaCl}, 1 \mathrm{~mm}$ EGTA, $1 \mathrm{~mm}$ $\mathrm{Na}_{3} \mathrm{VO}_{4}$, and $100 \mathrm{~mm} \mathrm{NaF}$ plus $5 \mu \mathrm{M} \mathrm{ZnCl} 2,10 \%$ glycerol, and $1 \%$ Triton X-100 and the following protease inhibitors: $10 \mu \mathrm{g} / \mathrm{ml}$ aprotinin, $1 \mu \mathrm{g} / \mathrm{ml}$ leupeptin, $1 \mathrm{~mm}$ PMSF, and $0.5 \mu \mathrm{M}$ okadaic acid. After homogenization and centrifugation at $100,000 \times g$ for $15 \mathrm{~min}$ at $4^{\circ} \mathrm{C}$, the resulting supernatants (lysates) were normalized for protein content (Lowry Assay, Bio-Rad Protein Assay Kit, Hercules, CA).

Western blot analysis (ERK phosphorylation). After electrophoretic separation the polyacrylamide gels were transferred onto polyvinylidene difluoride (PVDF) membranes (0.22 $\mu \mathrm{m}$ pore size, Bio-Rad), blocked overnight with $3 \%$ BSA (Fraction V, Sigma) in Tris-buffered saline containing $0.2 \%$ Tween 20 (TBS-T), and probed with the following antibodies: for ERK phosphorylation, rabbit anti-phospho-MAPK [dual phosphospecific (Thr202/Tyr204), 1:1000; New England Biolabs]; for ERK protein assessment, rabbit anti-ERK1 (1:1000) and rabbit antiERK2 (1:1000; Santa Cruz Biotechnologies, Santa Cruz, CA). Binding of the antibody to the membrane was detected by a secondary antibody (either goat anti-rabbit or goat anti-mouse) conjugated to horseradish peroxidase (HRP; 1:40,000; Pierce, Rockford, IL) and visualized on autoradiographic film, using enzyme-linked chemiluminescence (ECL; Amersham, Arlington Heights, IL). All blots were stripped and reprobed with the appropriate antibody to verify the equal loading of protein across lanes.

In-gel kinase assay (ERK activation). Nondenatured lysates were separated on a $10 \%$ polyacrylamide gel containing $0.6 \mathrm{mg} / \mathrm{ml}$ myelin basic protein (MBP; Upstate Biotechnology, Lake Placid, NY). Then the gel was washed with a $50 \mathrm{~mm}$ Tris, $\mathrm{pH} 8$, and $20 \%$ isopropanol solution and subsequently was denatured in Buffer A (consisting of $50 \mathrm{~mm}$ Tris, $\mathrm{pH} 8$, and $5 \mathrm{~mm}$ 2-mercaptoethanol), followed by treatment with $6 \mathrm{M}$ guanidinium-HCl in Buffer A. After renaturation in Buffer A containing $0.04 \%$ Tween 40 , the gel was exposed to the ATP mixture [containing 40 mM HEPES, pH 8, 1 mM $\mathrm{MnCl}_{2}, 2$ mM DTT, 0.1 mm EGTA, pH 7, 5 mM $\mathrm{MgCl}_{2}$, and $0.025 \mathrm{~mm}$ cold ATP plus $250 \mu \mathrm{Ci}$ of $\left[\gamma^{32} \mathrm{P}\right] \mathrm{ATP}$ (New England Nuclear, Wilmington, DE) per $10 \mathrm{ml}$ of ATP mixture] for $1 \mathrm{hr}$ at room temperature and washed extensively in 5\% TCA $1 \%$ sodium pyrophosphate solution. After the gel was dried onto Whatman filter paper, exposure to autoradiographic film allowed for the visualization of ${ }^{32} \mathrm{P}$-incorporated bands.

Immunoprecipitation of trk. Cerebral cortical explants were lysed as describe above. Lysates were immunoprecipitated with the rabbit antipan-trk (203) antibody (gift of D. R. Kaplan, Montreal Neurological Institute, Canada) overnight and precipitated with pre-BSA-blocked, protein A-Sepharose beads (Pharmacia Biotech, Uppsala, Sweden). After overnight incubation with protein A-Sepharose, the beads were washed four times with lysis buffer and subsequently were reconstituted in Laemmli buffer, boiled for $5 \mathrm{~min}$, and separated on a 7.5\% SDS-PAGE gel. The separated proteins were transferred onto PVDF membranes and probed with the mouse anti-phosphotyrosine (4G10) antibody (Upstate Biotechnology). Untreated PC12 cells and the trkA-deficient NNR-5 cell line served as negative controls, whereas NGF-treated PC12 cells served as the positive methodological control. Neurotrophin-treated cerebral cortical explants served as the internal experimental control.

$B$-Raf kinase assay. Cerebral cortical explants were lysed and immunoprecipitated with a rabbit anti-B-Raf antibody (Santa Cruz) and precipitated with anti-rabbit IgG-coated magnetic beads (Dynabeads, Dynal A. S., Oslo, Norway). After four washes with lysis buffer, the beads were used as the starting material for the B-Raf kinase assay. The assay procedure was done according to the protocol provided in the B-Raf 
kinase assay kit (Upstate Biotechnology) and is based on the phosphorylation of MBP by a B-Raf-activated kinase cascade that used radioactive ATP as the final phosphate donor. Briefly, assay dilution buffer [containing (in mM) 20 MOPS, $\mathrm{pH} 7.2,25 \beta$-glycerol phosphate, 5 EGTA, 1 $\mathrm{Na}_{3} \mathrm{VO}_{4}$, and 1 dithiothreitol] and the magnesium/cold ATP cocktail were added in conjunction with $0.4 \mu \mathrm{g}$ of inactive MEK1 and $1 \mu \mathrm{g}$ of inactive GST-p42 MAP kinase. Then this mixture was incubated for 30 $\min$ at $30^{\circ} \mathrm{C}$. Subsequently, additional assay dilution buffer, MBP, and $\left[\gamma^{-}{ }^{32} \mathrm{P}\right] \mathrm{ATP}$ were added and incubated for another $10 \mathrm{~min}$ at $30^{\circ} \mathrm{C}$ while being thoroughly shaken. After the samples were boiled for $5 \mathrm{~min}$, $25 \mu \mathrm{l}$ of the supernatant was spotted onto P81 phosphocellulose paper, which exhibits differential binding of the phosphorylated MBP from unincorporated ${ }^{32} \mathrm{P}$. Radioactivity incorporated into the $\mathrm{P} 81$ paper then was counted with a scintillation counter (Model Delta 300, Searle, Skokie, IL).

Coimmunoprecipitation of the ER with B-Raf, MEK1, and hsp90. Lysates obtained from explants were immunoprecipitated with either anti-ER antibody [ER715; National Hormone and Pituitary Program (NHPP), National Institute of Diabetes and Digestive and Kidney Diseases] or ER Ab C1355 (Friend et al., 1997) (gift of M. Shupnik, University of Virginia) or anti-MEK1 (Transduction Laboratories, Lexington, KY). Then the immunoprecipitates were separated and probed for various members of the putative complex. Lysates immunoprecipitated with the ER antibody were probed for MEK1, B-Raf, and hsp90. Negative controls were run in parallel, where a control (preimmune) IgG was used to immunoprecipitate the sample lysate, and subsequently probed with the appropriate antibody. Additionally, a control peptide or lysate was always used as a positive control to verify the identity of the band in the experimental lanes. In evaluating the presence of B-Raf kinase activity in the ER immunoprecipitates, we immunoprecipitated cerebral cortical lysates with either ER antibodies or preimmune $\operatorname{IgG}$, followed by precipitation with the Dynabeads. After four washes of the Dynabeads the resulting pellet was used as the starting material for the B-Raf kinase assay. In all coprecipitation experiments a detergent-free lysis buffer was used to wash the precipitates.

Densitometric analysis of ERK phosphorylation/activation time course. Autoradiograms were scanned with an Epson ActionScanner II (Epson America, Torrance, CA) and analyzed by Kodak 1D Image Analysis software (Eastman Kodak, Rochester, NY). Net intensity values were calculated by subtracting the background within the area measured for each band from the total intensity within this same measured area to account for any variation in background intensity across the film.

Statistical analysis. Resulting counts per minute (cpm) values obtained from the B-Raf kinase assay were analyzed by using a one way ANOVA, followed by Scheffé's post hoc analysis for group differences. Values obtained in comparing B-Raf kinase activity in control IgGimmunoprecipitated lysates versus ER-immunoprecipitated lysates were analyzed by using a two-tailed Student's $t$ test. All statistical analyses were performed by using the SPSS software (SPSS, Chicago, IL).

\section{RESULTS}

\section{Estradiol-induced phosphorylation and activation of ERK1 and ERK2}

To test whether estrogen signaling uses pathways also activated by neurotrophins in the developing brain, we investigated whether estrogen could elicit tyrosine phosphorylation and activation of ERK, a component of the MAP kinase cascade. 17- $\beta$ estradiol rapidly induced tyrosine phosphorylation of both ERK1 and ERK2. The responses were seen between 5 and $15 \mathrm{~min}$, became maximal at $1 \mathrm{hr}$, and declined to control levels by $4 \mathrm{hr}$ (Fig. 1). In addition, when explant cultures were treated with control media that did not contain estrogen or exogenously added neurotrophins, no increase in ERK phosphorylation was observed (data not shown), suggesting that the effect of estradiol on ERK phosphorylation was specific and not a consequence of procedural manipulation of the cultures. Furthermore, when cerebellar explants, a region of the brain that expresses considerably lower levels of estrogen binding, were treated for the same length of time that elicited maximal ERK phosphorylation in the cerebral

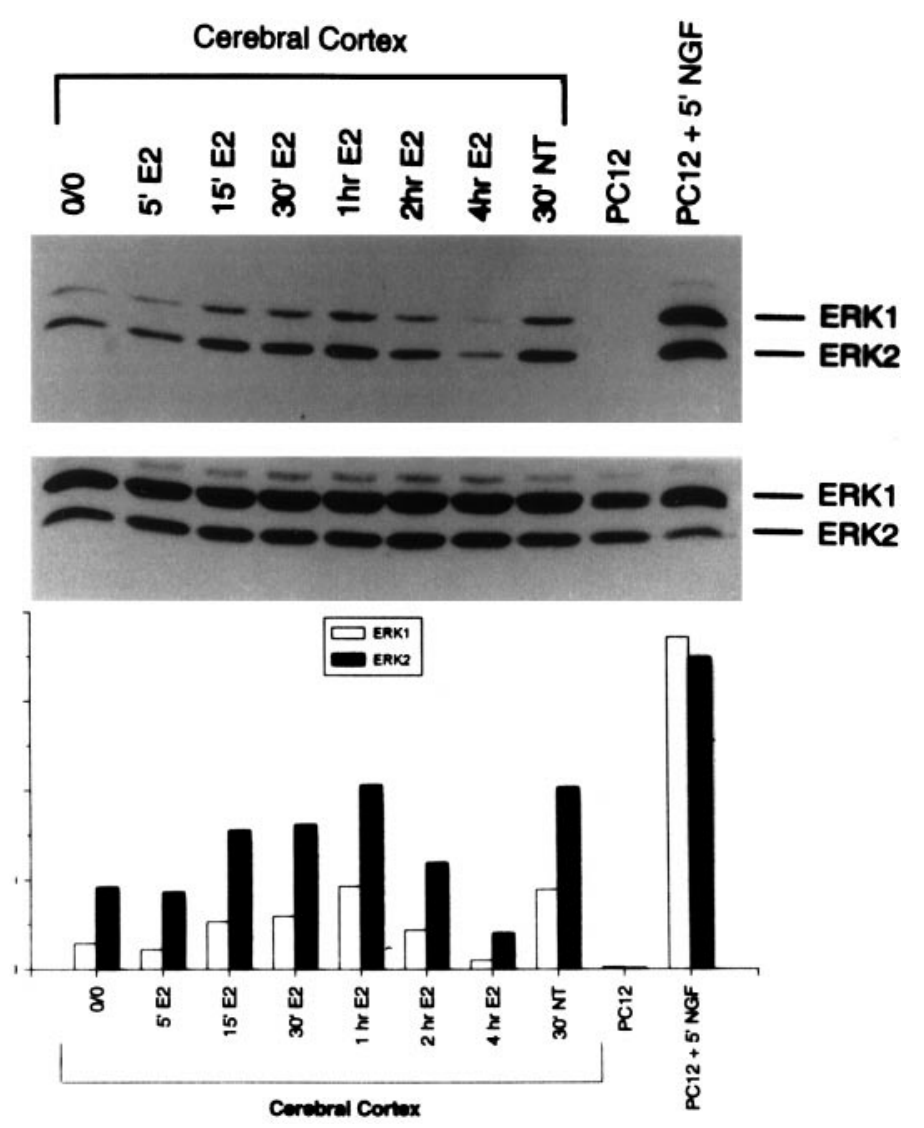

Figure 1. Estradiol-induced ERK phosphorylation. Lysates derived from cerebral cortical explants were probed with a phosphospecific ERK1/ ERK2 antibody. Shown is a time course for estradiol-induced ERK phosphorylation (top panel) and the reprobed blot for ERK1 and ERK2 protein (middle panel). Explants also were treated with a $100 \mathrm{ng} / \mathrm{ml}$ neurotrophin cocktail (NGF, BDNF, NT-3, and NT-4/5) for a single 30 min time point that served as the experimental positive control. Note the similarity in the intensity of the response to estrogen and the neurotrophins in the cortical explants. Untreated PC12 and NGF-treated PC12 cells served as negative and positive methodological controls, respectively. Densitometric representations of the relative intensities of the phosphorylated ERK1 and ERK2 bands are provided also (bottom panel).

cortex, little to no phosphorylation of ERK was detected (Fig. 2). Neurotrophin treatment, however, did result in ERK phosphorylation in the cerebellar explants (Fig. 2).

As expected, the neurotrophins also increased tyrosine phosphorylation of ERK1 and ERK2 in the cerebral cortical explants (see Fig. 1). The in-gel kinase assay (Fig. 3) demonstrates that phosphorylation of the ERKs correlated with an increase in ERK activity, because estradiol activation of ERK followed a similar time course observed in the ERK phosphorylation study (see Fig. 1).

\section{Pharmacological blockade of estradiol-induced ERK phosphorylation}

The effect of estradiol on ERK phosphorylation was not affected by the ER antagonists ICI 182,780 (Fig. 4A) or ICI 164,384 (data not shown). However, the MEK1 inhibitor PD98059 did inhibit the effect of both estradiol and the neurotrophins on ERK phosphorylation (Fig. 5). Furthermore, treatment with the MEK inhibitor alone also inhibited baseline phosphorylation of ERK. 


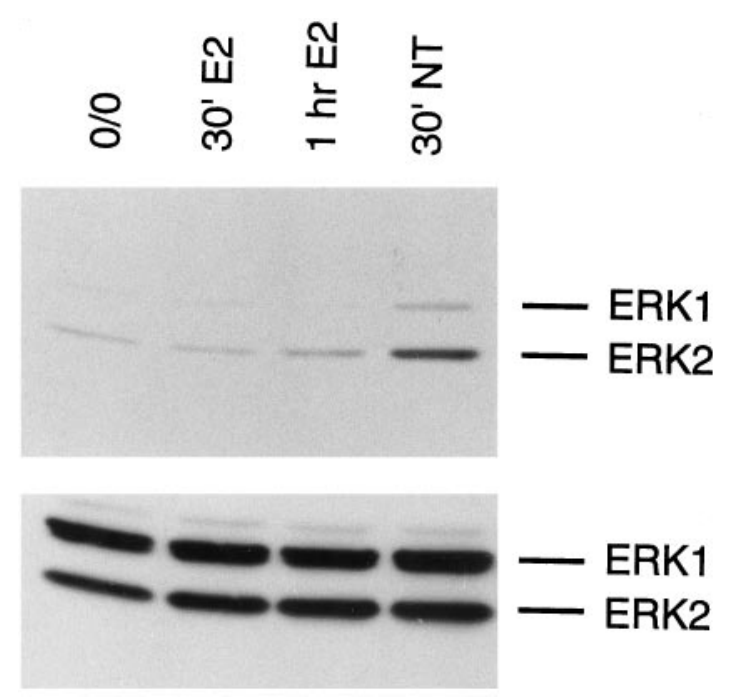

Figure 2. Effect of estradiol on ERK phosphorylation in cerebellar cultures. Cerebellar explants were treated with $10 \mathrm{~nm}$ estradiol for $30 \mathrm{~min}$ or for $1 \mathrm{hr}$. Only marginal phosphorylation of ERK was observed, whereas the neurotrophin cocktail treatment (positive control) resulted in robust phosphorylation of ERK. The bottom panel represents the same blot, which was stripped and reprobed for ERK1 and ERK2 protein to verify equal loading of protein across lanes.

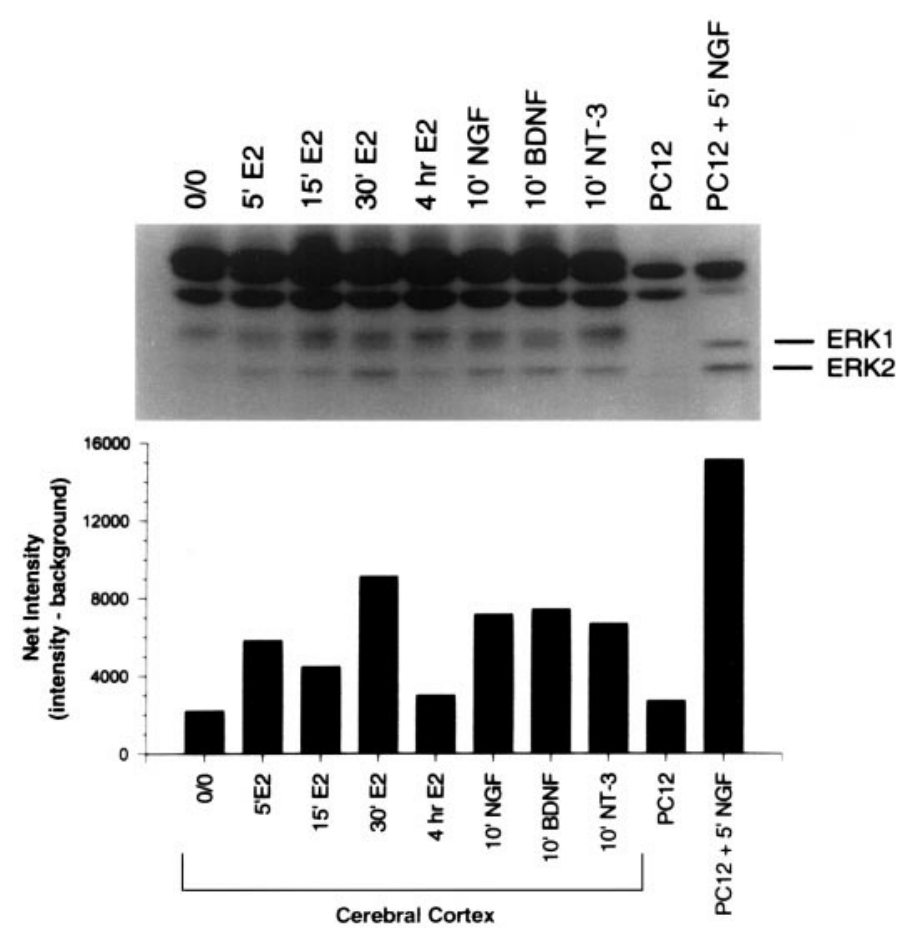

Figure 3. Temporal pattern of ERK activation after estradiol exposure. Shown is an in-gel kinase assay, using MBP as a substrate, for the temporal pattern of ERK1 and ERK2 activation in response to $10 \mathrm{nM}$ estradiol. The effects of $100 \mathrm{ng} / \mathrm{ml}$ of NGF, BDNF, or NT-3 on ERK activation were used as controls to document the action of all of these neurotrophins on ERK activation in cerebral cortical explants. Untreated PC12 cells and NGF-treated PC12 cells served as methodological controls. A densitometric representation of the relative intensities of ERK2 activation is provided also (bottom panel).
A

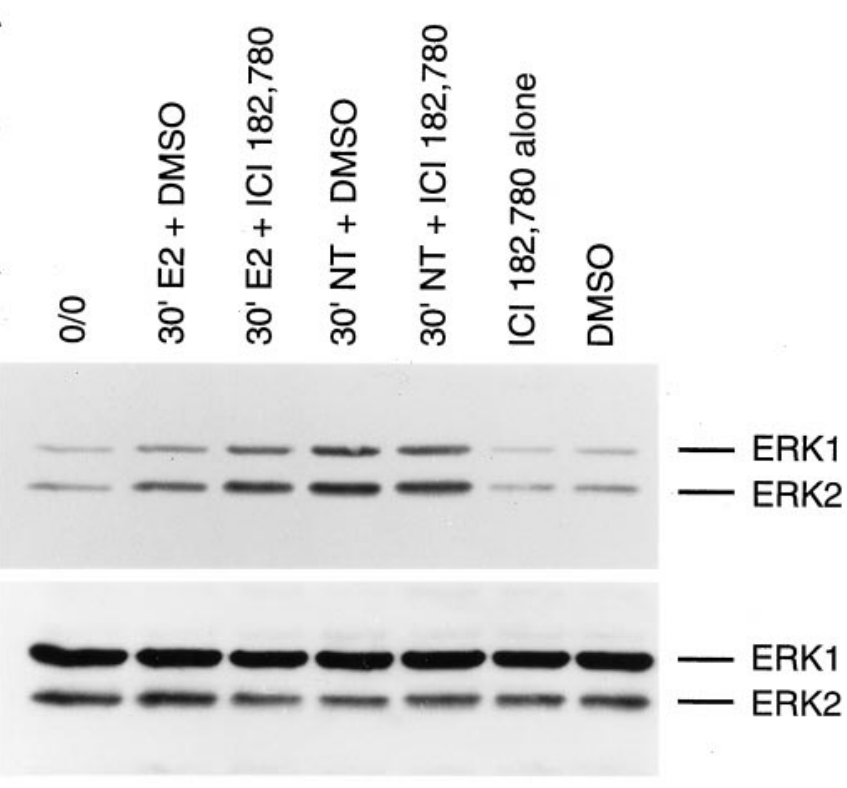

B

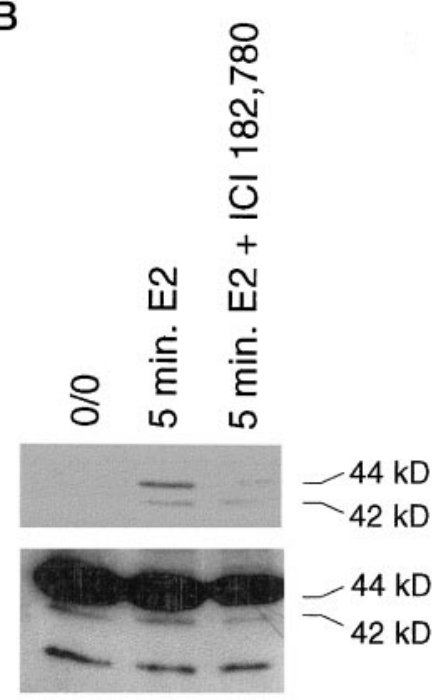

Figure 4. Effect of ICI 182,780 on estradiol-induced ERK phosphorylation in rat cerebral cortical explants. Cultures were pretreated with either vehicle (DMSO, $0.1 \%$ ) or $1 \mu \mathrm{M}$ ICI 182,780 for $24 \mathrm{hr}$ before being pulsed with either estradiol in combination with ICI 182,780 or estradiol with vehicle. $A$, Shown is the phospho-ERK blot documenting the inability of ICI 182,780 to block either estradiol- or neurotrophin-induced ERK phosphorylation. $B$, Documented is the positive control for the ICI 182,780 compound performed on the mammary tumor cell line, MCF-7, treated with either $10 \mathrm{~nm}$ estradiol or estradiol in combination with $10 \mu \mathrm{m}$ of ICI 182,780. The bottom panels in both $A$ and $B$ represent the same blot, which was stripped and reprobed for ERK1 and ERK2 protein to verify equal loading of protein across lanes.

\section{Estradiol-induced increase in B-Raf kinase activity}

The activity of the signaling protein B-Raf, which is immediately upstream of MEK, also was evaluated for responsiveness to estrogen exposure in cerebral cortical explants. Both the 30 and $60 \mathrm{~min}$ estradiol treatments resulted in significant increases in B-Raf activity relative to untreated controls (Fig. 6). In addition, the activation seen after $60 \mathrm{~min}$ of estradiol treatment was statistically equivalent to the activation of B-Raf observed after $30 \mathrm{~min}$ of neurotrophin treatment. 


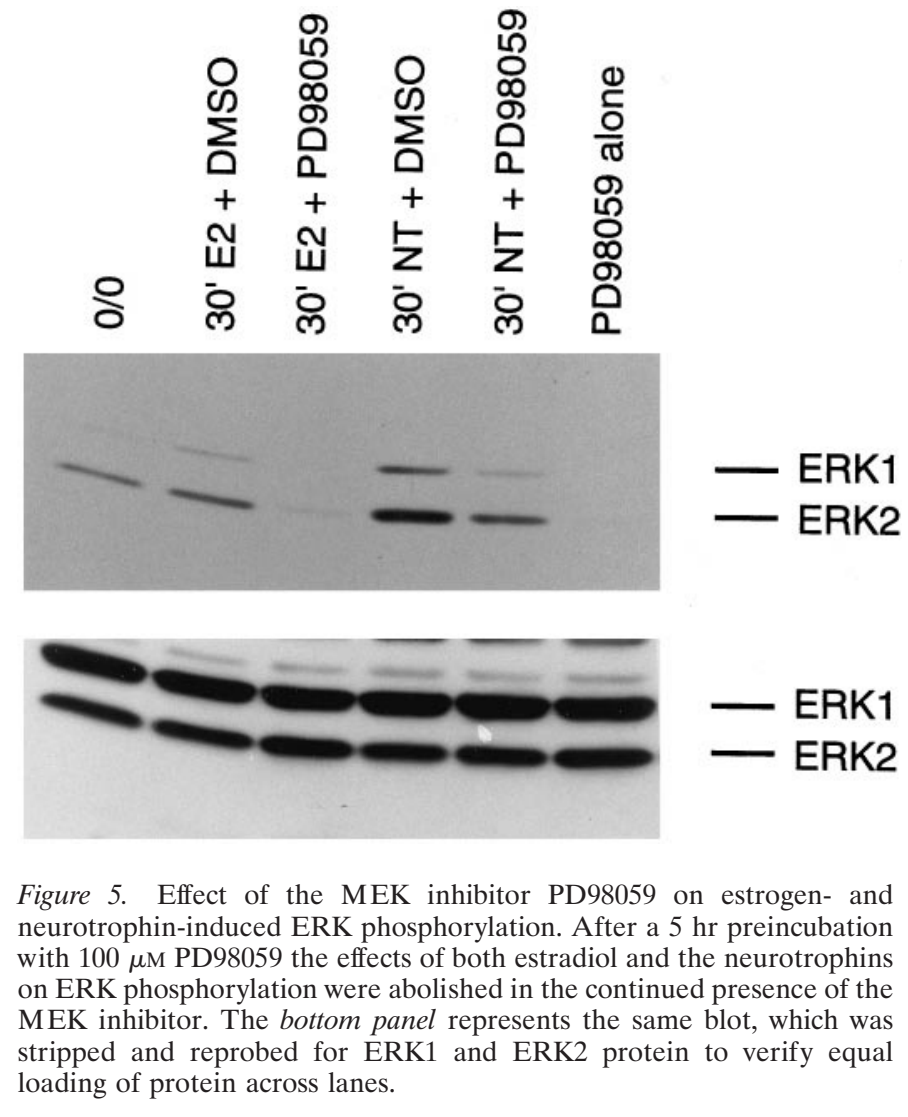

\section{Estradiol does not induce tyrosine phosphorylation of trk receptors}

To assess whether estradiol elicits the activation of ERK indirectly, i.e., via the release of endogenous neurotrophins that could result in the activation of trk, we investigated the ability of estradiol to induce tyrosine phosphorylation of the cortical trk receptors. After $30 \mathrm{~min}$ of estradiol treatment, a time point that elicited significant ERK phosphorylation, no increase in phosphorylation of $t r k$ receptors was observed. In contrast, a $30 \mathrm{~min}$ treatment with the neurotrophin cocktail (consisting of NGF, BDNF, NT-3, and NT-4/5) resulted in robust phosphorylation of trk (Fig. 7).

\section{Characterization of a putative complex containing the ER}

Western analysis of cerebral cortical lysates that used a B-Rafspecific antibody revealed significant levels of B-Raf (Fig. 8A). The intensity of the $95 \mathrm{kDa}$ band observed in the cerebral cortex was approximately one-half that observed in PC12 cells. Interestingly, a lower molecular weight isoform of B-Raf (68 kDa), known to be recognized by our B-Raf antibody (clone C-19; Santa Cruz), was seen only in the cerebral cortex and not in PC12 lysates (Fig. $8 A$ ). On the basis of the observation by Jaiswal and colleagues (1996), which documented an association between B-Raf and the heat shock protein hsp90 along with the well described association between hsp90 and the ER, we evaluated the potential association of the ER with B-Raf. Coprecipitation experiments in which cerebral cortical lysates were immunoprecipitated with anti-ER antibodies and subsequently probed with antibodies to B-Raf, in fact, revealed an association between the ER and B-Raf (Fig. $8 B$ ). A band of $\sim 95 \mathrm{kDa}$ was evident in the ER-immunoprecipitated lane and was conspicuously absent in the

\section{B-Raf Kinase Activity}

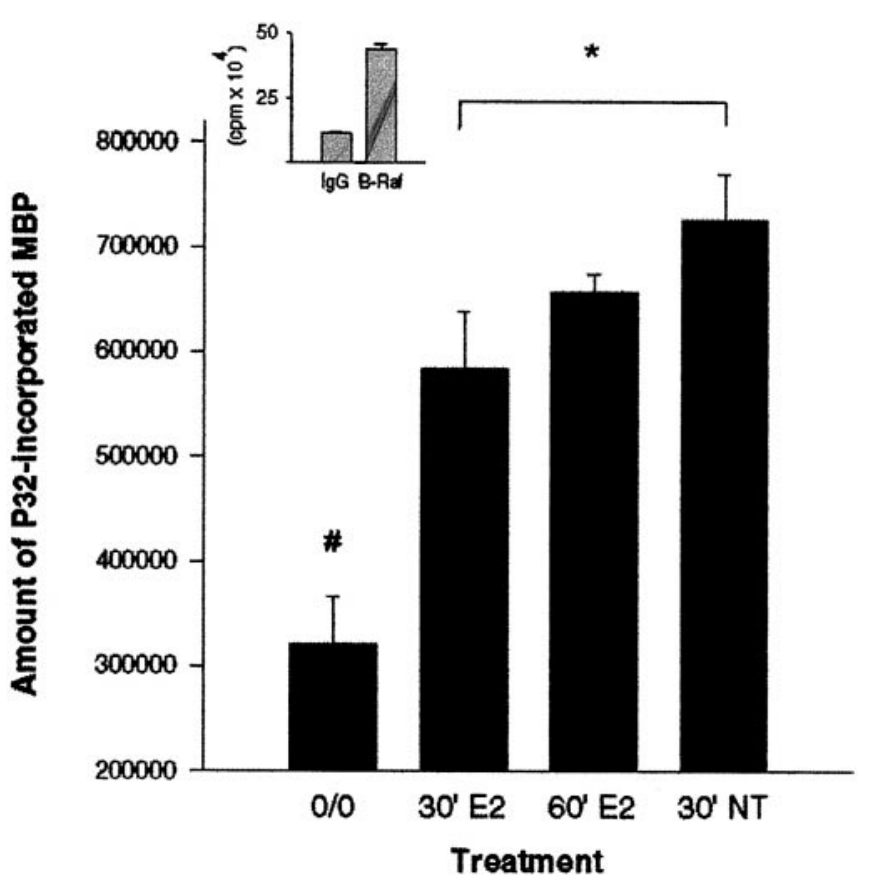

Figure 6. Effect of estradiol on B-Raf activity. The amount of ${ }^{32} \mathrm{P}$ incorporated into MBP was evaluated from lysates of cerebral cortical explants immunoprecipitated with the B-Raf antibody (clone C-19). Both 30 and $60 \mathrm{~min}$ estradiol treatment significantly increased the kinase activity of B-Raf relative to untreated control explants. Treatment of the explants with the neurotrophin cocktail for 30 min served as the experimental positive control and also revealed a significant increase in B-Raf kinase activity. Values represent the average of four samples and were calculated by subtracting the activity level obtained from an IgGimmunoprecipitated control (background) from the values obtained in the experimental samples. The difference (in $\mathrm{cpm}$ ) obtained after a control (untreated) sample was immunoprecipitated with preimmune $\mathrm{IgG}$ versus being immunoprecipitated with the B-Raf antibody is presented as the inset. Statistical analysis was performed by using a one-way ANOVA, followed by Scheffé's analysis for group differences (\#, different from all treated groups, $p<0.05$; *difference between $30^{\prime}$ E2 group and $30^{\prime} \mathrm{NT}$ group, with $p<0.05$ ).

IgG-immunoprecipitated lane. Although the slightly higher molecular weight band seen in the cerebral cortex relative to the PC12 cell band easily could be explained by the known existence of multiple B-Raf isoforms that are present in the brain (Barnier et al., 1995), we evaluated B-Raf kinase activity in the ERimmunoprecipitated explants to verify that the coprecipitated band observed was, in fact, kinase-active Raf. We found that lysates precipitated for ER did contain kinase-active Raf for which the activity was statistically higher than that observed in lysates immunoprecipitated with preimmune rabbit IgG (Fig. 8C). In additional experiments we evaluated the ER/B-Raf association in lysates from cerebral cortices of P10 rat pups. As was seen with the explants, after immunoprecipitation with the ER antibody, probing for B-Raf revealed a specific band $(\sim 95 \mathrm{kDa})$ that was not observed in the IgG-immunoprecipitated control lane (Fig. 9A). Subsequent reprobing for the ER revealed ER immunoreactivity $(67 \mathrm{kDa})$ in the ER-immunoprecipitated lane that was not observed in the IgG lane (Fig. 9B).

Immunoprecipitation with the anti-ER antibody, followed by probing with anti-hsp90, also revealed the expected association of 


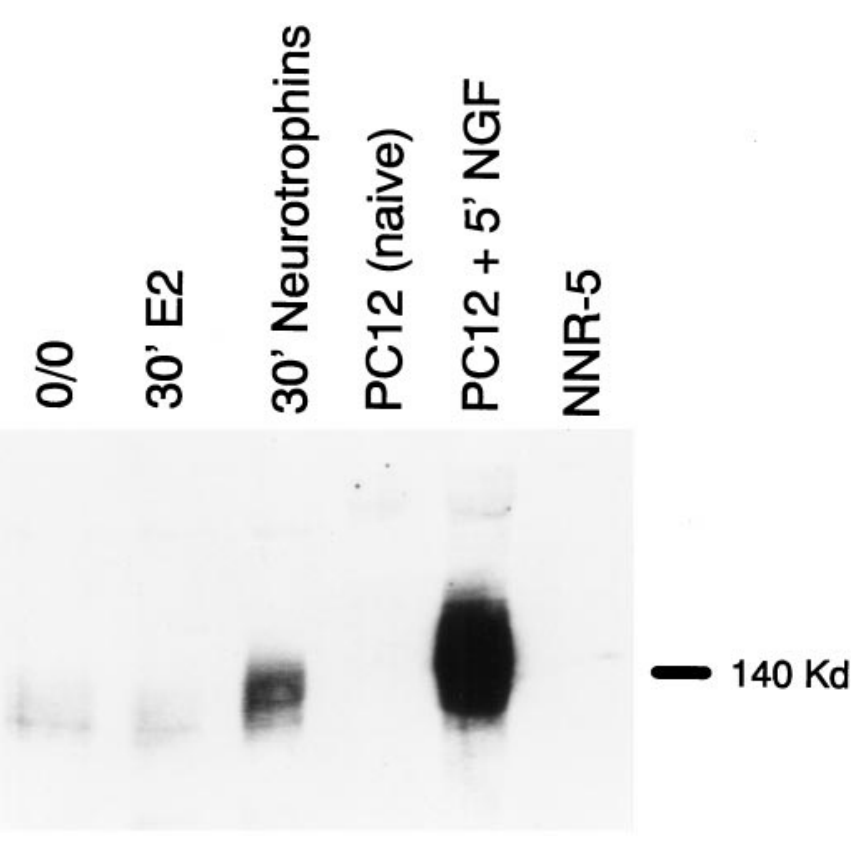

Figure 7. Effect of estradiol on trk phosphorylation. Lysates of cerebral cortical explants were immunoprecipitated with the pan-trk (203) antibody before Western analysis and probed with an anti-phosphotyrosine (4G10) antibody. Shown are the effects of a $30 \mathrm{~min}$ pulse of $10 \mathrm{~nm}$ estradiol and treatment with a $100 \mathrm{ng} / \mathrm{ml}$ neurotrophin cocktail for $30 \mathrm{~min}$. Estradiol did not elicit tyrosine phosphorylation of trk receptors, whereas the neurotrophins did. Untreated PC12 cells and the trk $A$-deficient NNR-5 cell line served as methodological negative controls, whereas NGFtreated PC12 cells served as the prototypical positive control.

hsp90 with the ER (Fig. 10A). The hsp90 band corresponded to the observed $90 \mathrm{kDa}$ band from the positive control (Fig. 10 A) and was markedly less in the negative control. The presence of a faint band in the negative control was attributed to the likely nonspecific association of hsp90 with protein A-Sepharose because of its sheer abundance in cells (1-2\% of total cellular protein). In contrast, immunoprecipitation of cerebral cortical lysates with anti-MEK1, followed by probing with the anti-ER antibody, failed to reveal an association between the ER and MEK1 (Fig. 10B). Similarly, reversal of the order of immunoprecipitation and probing antibodies also revealed a lack in association of the ER with MEK1 (Fig. 10C).

\section{DISCUSSION}

NGF, the prototypical neurotrophin, activates multiple signal transduction pathways, including the MAP kinase cascade, which serve to amplify and propagate signals generated at the cell surface into complex biological responses. Briefly, the MAP kinase cascade is propagated by Ras activation of Raf, followed by sequential phosphorylation and the activation of MEK and a member of the MAP kinase family, ERK. Activated ERK then can translocate to the nucleus to regulate transcription factors and immediate early and late response genes (Marshall, 1995).

In the present study we sought to identify an alternative estrogen signaling pathway that displayed similarities to the one used by growth factors, including the neurotrophins, and specifically the MAP kinase cascade. We document here for the first time in developing brain tissue, which expresses wild-type (normal) ERs, the estrogen-induced tyrosine phosphorylation of both ERK1 and ERK2. In contrast to the recent report by Migliaccio et al. (1996), which demonstrated transient estrogen-induced ERK activation in MCF-7 mammary carcinoma cells, the pattern of activation observed in the cerebral cortex in our study, although rapid in onset, was longer-lasting (up to at least $2 \mathrm{hr}$ ). Because sustained activation of ERK in PC12 cells has been associated with neuronal differentiation (Qui and Green, 1992; Marshall, 1995), the persistent ERK phosphorylation that followed estrogen exposure would appear to be consistent with the observed differentiative actions of estrogen on neurites (Toran-Allerand, 1976, 1980, 1984 ) in this culture system. Not all studies, however, support the sufficiency of ERK activation for neurite outgrowth. Some studies support the importance of ERK activation for neurite outgrowth (Qui and Green, 1992; Pang et al., 1995), whereas others oppose it (Kuo et al., 1996), citing the importance of Raf activation instead. Because estrogen elicits both B-Raf and ERK activation in the cerebral cortex, studies are currently underway to investigate whether estrogen activation of these specific nodes within the MAP kinase pathway could play a role in estrogen enhancement of neurite growth, using transfection strategies with dominant MEK, Raf, and Ras constructs.

Sustained activation of ERK has been reported to result in nuclear translocation of ERK (Traverse et al., 1992, 1994; Nguyen et al., 1993), which is then capable of regulating gene transcription itself (Davis, 1995). In contrast, mitogenic peptides (such as EGF in PC12 cells) elicit rapid but transient activation of ERK (Nguyen et al., 1993) unaccompanied by nuclear translocation. By acting via its own receptor, estrogen thus not only could elicit direct transcriptional effects (the classical mechanism) but also could regulate gene transcription indirectly via ERK activation. This alternative route of estrogen signaling may explain the ability of estrogen to regulate genes that do not exhibit an apparent canonical ERE (Sukovich et al., 1994).

The lack of inducible ERK phosphorylation by estradiol in the cerebellar explants also suggested that the estradiol-induced stimulation of ERK phosphorylation in the cerebral cortex may be a direct consequence of the presence of adequate ER levels and that the significantly lower levels of ER binding in the developing cerebellum (C. D. Toran-Allerand and N. J. MacLusky, unpublished observations) were insufficient for estrogen to elicit ERK phosphorylation. Interestingly, neither the ER antagonist ICI 182,780 nor ICI 164,384 was able to block estradiol-induced phosphorylation of ERK in the cerebral cortical explants. Because the efficacy of this and other ER antagonists has been characterized principally on the basis of their ability to prevent the transcriptional activation of ERE-containing genes, it is possible that this "nongenomic" effect of estradiol, by being upstream of any potential interaction with an ERE, may not be influenced by these antagonists. In agreement with this idea is the apparent lack of effect of either tamoxifen or ICI 182,780, two ER antagonists, on the effect of estrogen on MAPK in a human neuroblastoma tumor cell line (Watters et al., 1997). In the nonneuronal mammary tumor cell line, MCF-7, however, the ICI compound blocked the effect of estrogen on ERK activation (Migliaccio et al., 1996), which suggests that the effect of estrogen receptor antagonists also may be cell type-specific, possibly a consequence of differences in the ratios of ER subtypes within the cells.

To explore the mechanism and pathway(s) by which estradiol activated ERK, we first addressed the possibility that exposure of the cerebral cortical explants to estradiol elicited trk phosphorylation. Because estrogen has been reported to elicit tyrosine phosphorylation of the EGF receptor (Reddy et al., 1992), we first addressed the possibility that exposure of the cortical explants to 


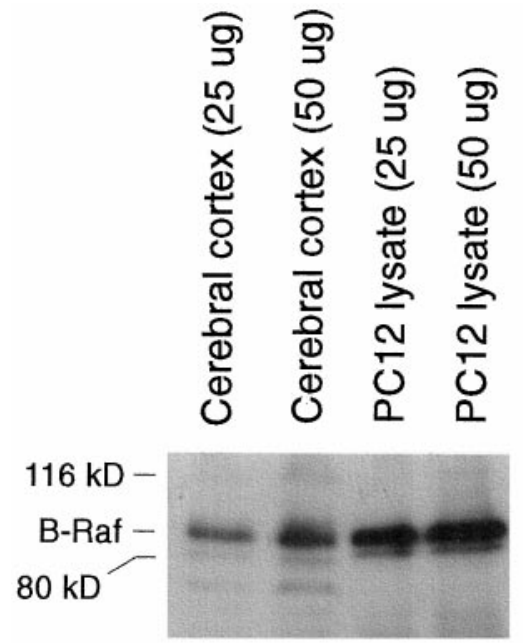

A

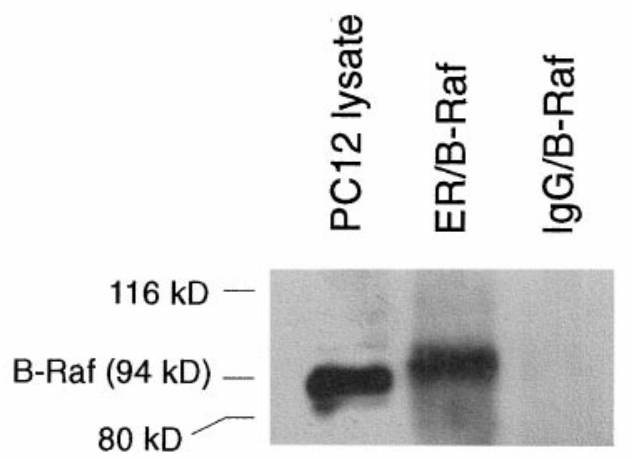

B

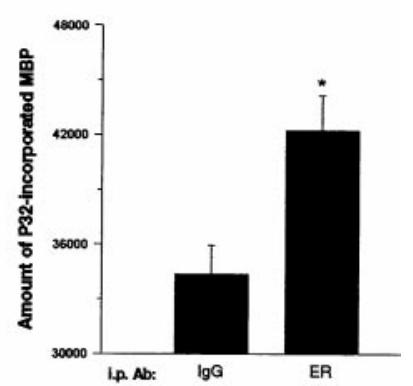

C

Figure 8. Coprecipitation of the ER with B-Raf in cerebral cortical explants. $A$, Evaluation of B-Raf levels in the cerebral cortical explants by Western analysis revealed significant levels of a $95 \mathrm{kDa}$ B-Raf band that migrated to a similar position as that observed in PC12 cells. An additional band of $\sim 68$ $\mathrm{kDa}$ also was observed in the cerebral cortical lysates that was absent in PC12 cell lysates. $B$, After immunoprecipitation with an anti-ER antibody (ER715), probing with an anti-B-Raf antibody revealed an association between the ER and the $95 \mathrm{kDa}$ isoform of B-Raf that was conspicuously absent in the IgG-immunoprecipitated lane. $C$, Confirmation of the identity of this specific B-Raf band as kinase-active Raf was performed by evaluating the amount of Raf activity present in cerebral cortical explants immunoprecipitated with the ER and comparing it with samples immunoprecipitated with preimmune IgG. Statistical analysis that used a two-tailed Student's $t$ test revealed that the level of Raf activity in the ER-immunoprecipitated samples was significantly higher than that observed in the IgG-immunoprecipitated control $(* p<0.05)$.

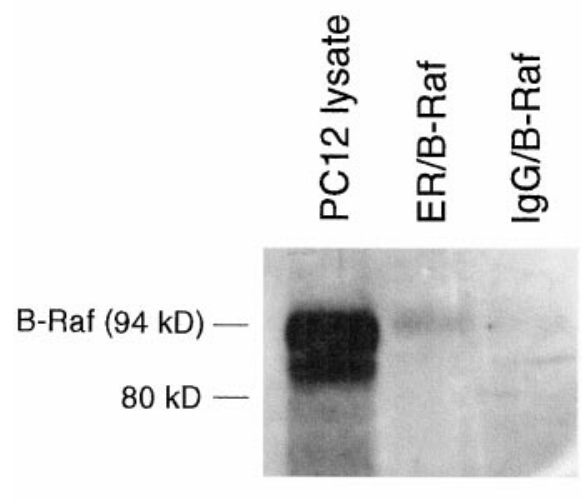

A

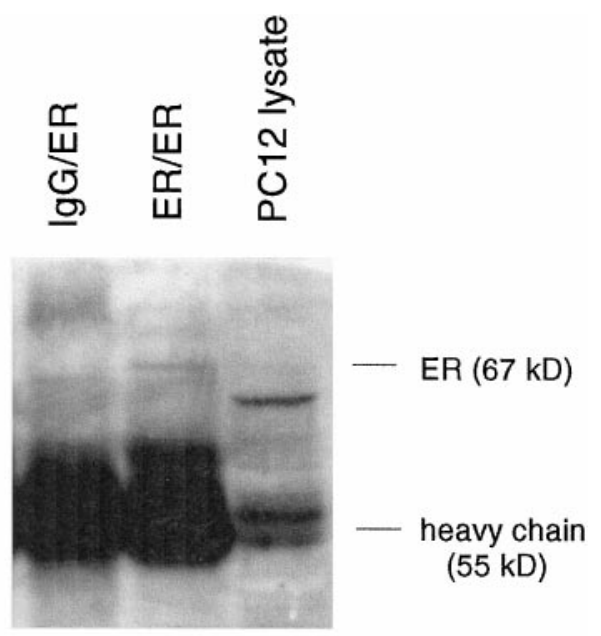

B

Figure 9. Coprecipitation of the ER and B-Raf in P10 cerebral cortical tissue. A, Immunoprecipitation of cerebral cortical lysates derived from P10 rat pups with the ER antibody, followed by Western analysis for B-Raf, revealed a similar association of B-Raf with the ER (as seen in explants of similar age), which was not found in the IgG-immunoprecipitated control. $B$, Subsequent reprobing of the blot for the ER revealed a specific ER (67 kDa) band that was not present in the IgG-immunoprecipitated control lane.

estradiol may have first elicited tyrosine phosphorylation of trk, either directly or as a result of estrogen-induced endogenous neurotrophin release. As such, this would initiate the cascade of events that follows trk autophosphorylation, eventually leading to ERK activation. Estradiol was without effect in this regard, whereas neurotrophin exposure did elicit trk phosphorylation, supporting the hypothesis that the effect of estradiol is not simply attributable to the release of endogenous neurotrophins or to trk activation. Second, the ability of the MEK1 inhibitor PD98059 to inhibit estrogen-induced phosphorylation of ERK suggests the involvement of MEK1 in the estrogen signaling pathway. Finally, our observation of estradiol-induced activation of B-Raf also implicates B-Raf in the cross-coupling of the ER and neurotrophin signaling pathways. Together, these observations support the hypothesis that convergence of the ER and neurotrophin receptor signaling pathways occurs downstream of trk and begins at least at the level of B-Raf, or perhaps further upstream.

Recent studies by Jaiswal et al. (1996) have documented an 


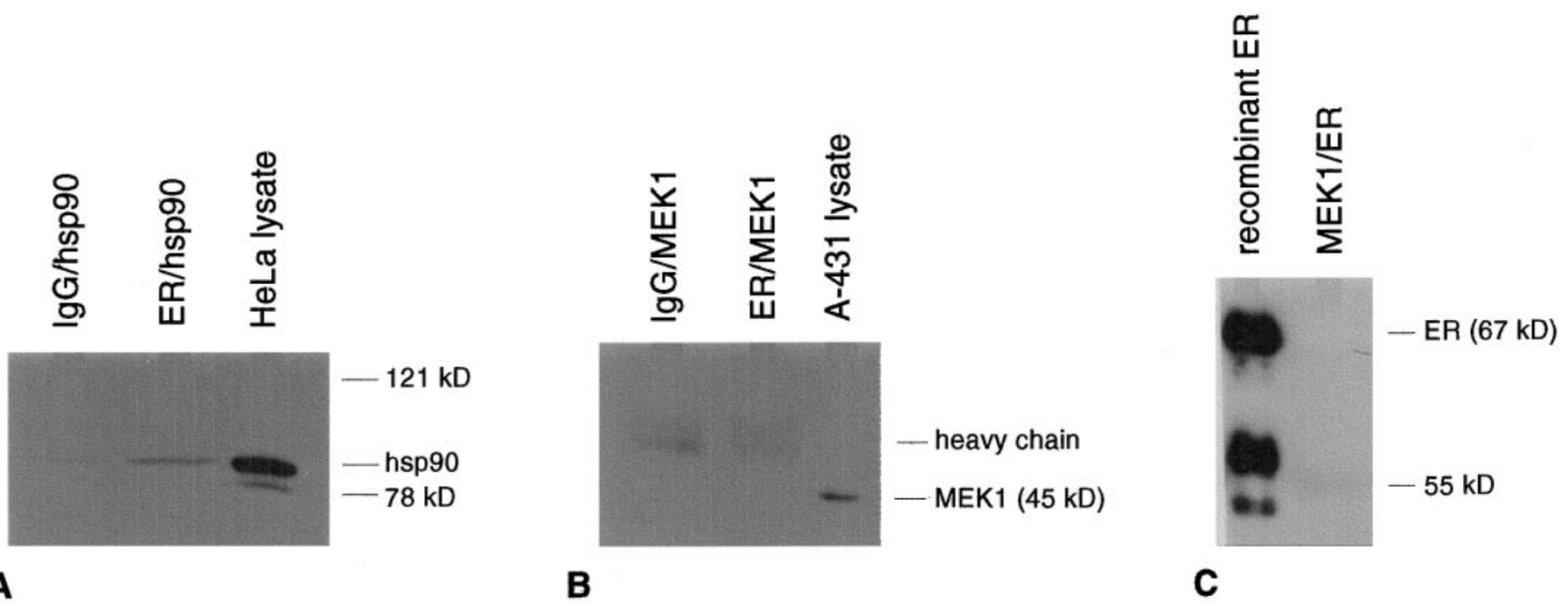

Figure 10. Coimmunoprecipitation of the ER with hsp90, but not with MEK1. A, Immunoprecipitation with the ER and probing for hsp90 revealed an association in the ER with hsp90. The HeLa lysate served as a positive control for the detection of hsp90. Immunoprecipitation with either anti-MEK1 $(B)$ or the ER $(C)$ failed to reveal an association between the ER and MEK1. Recombinant estrogen receptor protein $(C)$ and A-431 lysate $(B)$ served as positive controls for the detection of the ER and MEK1, respectively.

intracellular complex formed by the association of hsp90 with a member of the trk signaling cascade, B-Raf. This intracellular complex had a molecular weight that was $>300 \mathrm{kDa}$, suggesting the possibility of additional components within this complex. Because the ER has been well documented to associate with hsp90 (Ratajczak et al., 1990; Segnitz and Gehring, 1995), we addressed the possibility that the ER may be part of a multimeric complex consisting of at least B-Raf, MEK1, and hsp90. The results showed a clear association of the ER with B-Raf and hsp90, although not with MEK. The B-Raf band observed in the cerebral cortical explant sample seemed to migrate to a slightly higher molecular weight $(\sim 95-96 \mathrm{kDa})$ than that observed in PC12 cells ( $\sim 94 \mathrm{kDa})$. Although multiple isoforms of B-Raf have been documented in the brain, ranging from 86 to $99 \mathrm{kDa}$ (Barnier et al., 1995), it was necessary to ensure that the band was, in fact, kinase-active Raf. As such, we found that ER immunoprecipitates did contain kinase-active Raf, for which the activity was significantly higher than that observed in IgG-immunoprecipitated cerebral cortical lysates. In addition, coimmunoprecipitation also was performed with cerebral cortical tissue derived from P10 rats and revealed a similar association that was absent in controls (see Fig. 9A), further supporting that the association of the ER with $\mathrm{B}-\mathrm{Raf}$ is real and not simply a consequence of the culture system.

Thus, the initial route taken to elicit rapid activation of ERK may involve direct activation of this putative multimeric complex via dissociation and conformational changes consequent to phosphorylation of one or more of the already identified ER/signaling proteins associated within the complex. Alternatively, estradiol may induce a greater association of B-Raf into this complex. This recruitment could then instruct, via phosphorylation, further downstream members of the cascade, such as MEK and ERK, to become rapidly activated. Such a putative multimeric complex or complexes, consisting of the ER and members of the MAP kinase cascade, could serve as an intracellular junction linking the estrogen and neurotrophin signaling pathways. Thus, cross-coupling of the ER with growth factor signaling pathways, which appears to be a general property of the ER (Kato et al., 1995; Bunone et al., 1996), may argue for a mutual requirement of both the estrogen and the neurotrophin systems to elicit their effects efficiently, if not completely.

Finally, with the discovery of ER- $\beta$ (Kuiper et al., 1996) we cannot exclude the possibility that the effect of estrogen on ERK activation may occur either via this novel receptor, a proposed membrane-associated estrogen receptor (Pietras and Szego, 1977; Pappas et al., 1995; Karthikeyan and Thampan, 1996), or even an as yet unidentified ER. Thus, it is possible that more than one subtype of the ER could interact with this putative complex. The sum of these findings suggests that, depending on the ER subtype (for example, $\alpha$ vs $\beta$ ) or cellular location (membrane vs cytosolic vs nuclear) or even on hormonal or growth factor milieu, the ER and various signaling proteins may coexist in a variety of multimeric associations or complexes. Experiments directed to understand the nature of the complex(es) after various treatments are currently underway.

Although our results document the involvement of ERK in estrogen signaling, they do not rule out the involvement of other substrates such as adenylate cyclase/cAMP (Aronica et al., 1994) or $\mathrm{Ca}^{2+}$ channels (Morley et al., 1992) in the mechanism of estrogen action. These substrates also may act, either in parallel or by converging into the MAP kinase pathway, to elicit estrogeninduced differentiation of neurons. Nevertheless, the existence of ERs in multimeric complexes with growth factor signaling proteins creates the potential for a broader scope of the actions of estrogen and provides support for alternative signal transduction pathways underlying the differentiative effects of estrogen on CNS tissue. Although the traditional view of estrogen action has been that the ligand-activated ER binds directly to EREs, our findings could explain how estrogen and the neurotrophins, via the intermediary of ERK translocation into the nucleus, could regulate the same broad array of ERE-containing genes such as GAP-43 (Costello et al., 1990; Lustig et al., 1991) and tau microtubule-associated protein (Drubin et al., 1985; Matsuno et al., 1997) and non-ERE-containing genes such as $\beta$-tubulin (Guo and Gorski, 1988) and MAP-2 (Black et al., 1986; Fischer et al., 1991; Lorenzo et al., 1992) involved in neuronal differentiation and neurite growth. 


\section{REFERENCES}

Aronica SM, Kraus WL, Katzenellenbogen BS (1994) Estrogen action via the cAMP signaling pathway: stimulation of adenylate cyclase and cAMP-regulated gene transcription. Proc Natl Acad Sci USA 91:8517-8521.

Barnier JV, Papin C, Eychene A, Lecoq O, Calothy G (1995) The mouse $B$-raf gene encodes multiple protein isoforms with tissue-specific expression. J Biol Chem 270:23381-23389.

Black M, Aletta J, Greene L (1986) Regulation of microtubule composition and stability during nerve growth factor-promoted neurite outgrowth. J Cell Biol 103:545-557.

Bunone G, Briand PA, Miksicek RJ, Picard D (1996) Activation of the unliganded estrogen receptor by EGF involves the MAP kinase pathway and direct phosphorylation. EMBO J 15:2174-2183.

Chiaia N, Foy M, Teyler TJ (1983) The hamster hippocampal slice. II. Neuroendocrine modulation. Behav Neurosci 97:839-843.

Costello B, Meymandi A, Freeman J (1990) Factors influencing GAP-43 gene expression in $\mathrm{PC} 12$ pheochromocytoma cells. J Neurosci 10:1398-1406

Davis RJ (1995) Transcriptional regulation by MAP kinases. Mol Reprod Dev 42:459-467.

Drubin D, Feinstein S, Shooter E, Kirschner M (1985) Nerve growth factor-induced neurite outgrowth in PC12 cells involves the coordinate induction of microtubule assembly and assembly-promoting factors. J Cell Biol 101:1799-1807.

Fischer I, Richter-Landsberg C, Safaei R (1991) Regulation of microtubule-associated protein 2 (MAP2) expression by nerve growth factor in PC12 cells. Exp Cell Res 194:195-201.

Friedman WJ, McEwen BS, Toran-Allerand CD, Gerlach JL (1983) Perinatal development of hypothalamic and cortical estrogen receptors in mouse brain: methodological aspects. Brain Res 313:19-27.

Friend KE, Resnick EM, Ang LW, Shupnik MA (1997) Specific modulation of estrogen receptor mRNA isoforms in rat pituitary throughout the estrous cycle and in response to steroid hormones. Mol Cell Endocrinol 131:147-155.

Garcia-Segura LM, Olmos G, Tranque P, Naftolin F (1987) Rapid effects of gonadal steroids upon hypothalamic neuronal membrane ultrastructure. J Steroid Biochem 27:615-623.

Gerlach JL, McEwen BS, Toran-Allerand CD, Friedman WJ (1983) Perinatal development of estrogen receptors in mouse brain assessed by radioautography, nuclear isolation, and receptor assay. Brain Res 313:7-18.

Guo JZ, Gorski J (1988) Estrogen effects on histone messenger ribonucleic acid levels in the rat uterus. Mol Endocrinol 2:693-700.

Ignar-Trowbridge DM, Nelson KG, Bidwell MC, Curtis SW, Washburn TF, McLachlan JA, Korach KS (1992) Coupling of dual signaling pathways: epidermal growth factor action involves the estrogen receptor. Proc Natl Acad Sci USA 89:4658-4662.

Jaiswal RK, Weissinger E, Kolch W, Landreth GE (1996) Nerve growth factor-mediated activation of the mitogen-activated protein (MAP) kinase cascade involves a signaling complex containing B-Raf and HSP90. J Biol Chem 271:23626-23629.

Karthikeyan N, Thampan RV (1996) Plasma membrane is the primary site of localization of the nonactivated estrogen receptor in the goat uterus: hormone binding causes receptor internalization. Arch Biochem Biophys 325:47-57.

Kato S, Endoh H, Masuhiro Y, Kitamoto T, Uchiyama S, Sasaki H, Masushige S, Gotoh Y, Nishida E, Kawashima H, Metzger H, Chambon $\mathrm{P}$ (1995) Activation of the estrogen receptor through phosphorylation by mitogen-activated protein kinase. Science 270:1491-1494.

Kuiper GG, Enmark E, Pelto-Huikko M, Nilsson S, Gustafsson JA (1996) Cloning of a novel receptor expressed in rat prostate and ovary. Proc Natl Acad Sci USA 93:5925-5930.

Kuo WL, Abe M, Rhee J, Eves EM, McCarthy SA, Yan M, Templeton DJ, McMahon M, Rosner MR (1996) Raf, but not MEK or ERK, is sufficient for differentiation of hippocampal neuronal cells. Mol Cell Biol 16:1458-1470.

Lorenzo A, Diaz H, Carrer H, Caceres A (1992) Amygdala neurons in vitro: neurite growth and effects of estradiol. J Neurosci Res 33:418-435.

Lustig R, Sudol M, Pfaff D, Federoff H (1991) Estrogenic regulation and sex dimorphism of growth-associated protein $43 \mathrm{kDa}$ (GAP-43) messenger RNA in the rat. Brain Res Mol Brain Res 11:125-132.

Marshall C (1995) Specificity of receptor tyrosine kinase signaling: tran- sient versus sustained extracellular signal-regulated kinase activation. Cell 80:179-185.

Matsuno A, Takekoshi S, Sanno N, Utsunomiya H, Ohsugi Y, Saito N, Kanemitsu H, Tamura A, Nagashima T, Osamura RY, Watanabe K (1997) Modulation of protein kinases and microtubule-associated proteins and changes in ultrastructure in female rat pituitary cells: effects of estrogen and bromocriptine. J Histochem Cytochem 45:805-813.

Migliaccio A, Pagano M, Auricchio F (1993) Immediate and transient stimulation of protein tyrosine phosphorylation by estradiol in MCF-7 cells. Oncogene 8:2183-2191.

Migliaccio A, Di Domenico M, Castoria G, de Falco A, Bontempo P, Nola E, Auricchio F (1996) Tyrosine kinase/p21ras/MAP-kinase pathway activation by estradiol-receptor complex in MCF-7 cells. EMBO J 15:1292-1300.

Miranda RC, Sohrabji F, Toran-Allerand CD (1993) Neuronal colocalization of mRNAs for neurotrophins and their receptors in the developing central nervous system suggests a potential for autocrine interactions. Proc Natl Acad Sci USA 90:6439-6443.

Miranda RC, Sohrabji F, Singh M, Toran-Allerand CD (1996) Nerve growth factor (NGF) regulation of estrogen receptors in explant cultures of the developing forebrain. J Neurobiol 31:77-87.

Morley P, Whitfield JF, Vanderhyden BC, Tsang BK, Schwartz JL (1992) A new, nongenomic estrogen action: the rapid release of intracellular calcium. Endocrinology 131:1305-1312.

Nguyen TT, Scimeca JC, Filloux C, Peraldi P, Carpentier JL, Van Obberghen E (1993) Coregulation of the mitogen-activated protein kinase, extracellular signal-regulated kinase 1 , and the $90 \mathrm{kDa}$ ribosoma S6 kinase in PC12 cells. Distinct effects of the neurotrophic factor, nerve growth factor, and the mitogenic factor, epidermal growth factor. J Biol Chem 268:9803-9810.

Pang L, Sawada T, Decker SJ, Saltiel AR (1995) Inhibition of MAP kinase kinase blocks the differentiation of PC -12 cells induced by nerve growth factor. J Biol Chem 270:13585-13588.

Pappas TC, Gametchu B, Watson CS (1995) Membrane estrogen receptors identified by multiple antibody labeling and impeded-ligand binding. FASEB J 9:404-410.

Patrone C, Ma ZQ, Pollio G, Agrati P, Parker MG, Maggi A (1996) Cross-coupling between insulin and estrogen receptor in human neuroblastoma cells. Mol Endocrinol 10:499-507.

Pietras RJ, Szego CM (1977) Specific binding sites for oestrogen at the outer surfaces of isolated endometrial cells. Nature 265:69-72.

Qui MS, Green SH (1992) PC12 cell neuronal differentiation is associated with prolonged p21ras activity and consequent prolonged ERK activity. Neuron 9:705-717.

Ratajczak T, Hlaing J, Brockway MJ, Hahnel R (1990) Isolation of untransformed bovine estrogen receptor without molybdate stabilization. J Steroid Biochem 35:543-553.

Read L, Greene G, Katzenellenbogen B (1989) Regulation of estrogen receptor messenger ribonucleic acid and protein levels in human breast cancer cell lines by sex steroid hormones, their antagonists, and growth factors. Mol Endocrinol 3:295-304.

Reddy KB, Mangold GL, Tandon AK, Yoneda T, Mundy GR, Zilberstein A, Osborne CK (1992) Inhibition of breast cancer cell growth in vitro by a tyrosine kinase inhibitor. Cancer Res 52:3636-3641.

Segnitz B, Gehring U (1995) Subunit structure of the nonactivated human estrogen receptor. Proc Natl Acad Sci USA 92:2179-2183.

Singh M, Meyer EM, Simpkins JW (1995) The effect of ovariectomy and estradiol replacement on brain-derived neurotrophic factor messenger ribonucleic acid expression in cortical and hippocampal brain regions of female Sprague Dawley rats. Endocrinology 136:2320-2324.

Sohrabji F, Greene L, Miranda R, Toran-Allerand C (1994a) Reciprocal regulation of estrogen and NGF receptors by their ligands in PC12 cells. J Neurobiol 25:974-988.

Sohrabji F, Miranda RC, Toran-Allerand CD (1994b) Estrogen differentially regulates estrogen and nerve growth factor receptor mRNAs in adult sensory neurons. J Neurosci 14:459-471.

Sohrabji F, Miranda RC, Toran-Allerand CD (1995) Identification of a putative estrogen response element in the gene encoding brain-derived neurotrophic factor. Proc Natl Acad Sci USA 92:11110-11114.

Sukovich DA, Mukherjee R, Benfield PA (1994) A novel, cell-typespecific mechanism for estrogen receptor-mediated gene activation in the absence of an estrogen-responsive element. Mol Cell Biol 14:7134-7143.

Toran-Allerand CD (1976) Sex steroids and the development of the 
newborn mouse hypothalamus and preoptic area in vitro: implications for sexual differentiation. Brain Res 106:407-412.

Toran-Allerand CD (1980) Sex steroids and the development of the newborn mouse hypothalamus and preoptic area in vitro. II. Morphological correlates and hormonal specificity. Brain Res 189:413-427.

Toran-Allerand CD (1984) On the genesis of sexual differentiation of the general nervous system: morphogenetic consequences of steroidal exposure and possible role of alpha-fetoprotein. Prog Brain Res 61:63-98.

Toran-Allerand CD (1996a) The estrogen/neurotrophin connection during neural development: is colocalization of estrogen receptors with the neurotrophins and their receptors biologically relevant? Dev Neurosci 18:36-48.

Toran-Allerand CD (1996b) Mechanisms of estrogen action during neural development: mediation by interactions with the neurotrophins and their receptors? J Steroid Biochem Mol Biol 56:169-178.

Toran-Allerand CD, Miranda R, Bentham W, Sohrabji F, Brown T, Hochberg R, MacLusky N (1992) Estrogen receptors colocalize with low-affinity nerve growth factor receptors in cholinergic neurons of the basal forebrain. Proc Natl Acad Sci USA 89:4668-4672.

Traverse S, Gomez N, Paterson H, Marshall C, Cohen P (1992) Sustained activation of the mitogen-activated protein (MAP) kinase cascade may be required for differentiation of PC12 cells. Comparison of the effects of nerve growth factor and epidermal growth factor. Biochem J 288:351-355.

Traverse S, Seedorf K, Paterson H, Marshall CJ, Cohen P, Ullrich A (1994) EGF triggers neuronal differentiation of PC12 cells that overexpress the EGF receptor. Curr Biol 4:694-701.

Watters JJ, Campbell JS, Cunningham MJ, Krebs EG, Dorsa DM (1997) Rapid membrane effects of steroids in neuroblastoma cells: effects of estrogen on mitogen-activated protein kinase signaling cascade and $c$-fos immediate early gene transcription. Endocrinology 138: $4030-4033$.

Zhou Y, Watters J, Dorsa D (1996) Estrogen rapidly induces the phosphorylation of the cAMP response element binding protein in rat brain. Endocrinology 137:2163-2166. 